\title{
Virtual Principle for Determination Initial Displacements of Reinforced Concrete and Prestressed Concrete (Overtop) Members
}

\author{
Mirko Balabušić \\ Independent Designer of Structure, Hercg Novi, Montenegro \\ Email: balabusicm@gmail.com
}

How to cite this paper: Balabušić, $M$. (2021) Virtual Principle for Determination Initial Displacements of Reinforced Concrete and Prestressed Concrete (Overtop) Members. Open Journal of Civil Engineering, 11, 235-253.

https://doi.org/10.4236/ojce.2021.112015

Received: December 21, 2020

Accepted: June 27, 2021

Published: June 30, 2021

Copyright $\odot 2021$ by author(s) and Scientific Research Publishing Inc. This work is licensed under the Creative Commons Attribution International License (CC BY 4.0).

http://creativecommons.org/licenses/by/4.0/

\begin{abstract}
Theoretical approach with analytical and numerical procedure for determination initial displacement of a reinforced and prestressed concrete members, simple and cantilever beams, loaded by axial forces and bending moments is proposed. It is based on the principle of minimum potential energy with equality of internal and external forces. The equations for strain internal energy have been derived, including compressed and tensile concrete and reinforcement. The energy equations of the external forces with axial flexural displacement effects have been derived from the assumed sinusoidal curve. The trapezoid rule is applied to integrate the segment strain energy. The proposed method uses a non-linear stress-strain curve for the concrete and bilinear elastic-plastic relationship for reinforcement; equilibrium conditions at a sectional level to generate the strain energies along the beam. At the end of this article are shown three specific numerical examples with comparative, experimental (two tests) results with the excellent agreement and one calculation result with a great disagreement, by obtaining results of virtual principle method. With this method is avoiding the adoption of an unsure (EJ), as in the case of underestimating or overestimate initial flexural rigidity.
\end{abstract}

\section{Keywords}

Virtual Principle, Strain and External Energy, Reinforced and Prestresed Beam

\section{Introduction}

The mechanics of continuous environments in dealing with the stress and strain distribution under the influence of external forces start from the assumption that the substance is continuous and therefore deformations are treated as conti- 
nuous transformations of the space in which the stressed body exists.

Some changes occur immediately after a change in stress condition and thus are called initial deformations. The equilibrium process of deformation of elastic bodies under linear interconnection between stress and deformation is the subject of the study of classical elastic theory and falls into reversible processes. A more complete theoretical treatment of the occurrence of increasing material deformation was carried out by the Austrian physicist L. Boltzman, who formulated a theory of subsequent elastic action and laid foundations for a linear theory of flow. The deflection [1] (Branson, D.F. and Shaikh, A.F., 1985) of the prestressed concrete beams is calculated with simple equations by modifying some of the existing methods. The comparison between the experimental and theoretical results shows good agreement. Many reinforced and prestressed concrete bridges throughout the world are either deteriorated or distressed to such a degree that structural strengthening of the bridge or reducing the allowable is necessary to extend the service life of the bridge.

While several methods are available in the literature for evaluation of deflections, this chapter concentrates on the effective moment of inertia method in [2] Building Code Requirements for Reinforced Concrete (ACI 318) and modifications introduced by ACI Committee. These reports include [3] ACI 435.2R, "Deflection of Reinforced Concrete Flexural Members", and [4] ACI 435.1R, "Deflection of Prestressed Concrete Members". The report replaces several reports of this committee (ACI 318) in order to reflect the more recent state of the art in design. The recommendations of current codes show that most of them underestimate or overestimate the initial flexural rigidity.

Simplified method of ACI. According to ACI 318 Building Code [2] instantaneous displacement of reinforced concrete beams, shall be computed with effective moment of inertia $J_{c}$, given by

$$
J_{e}=\left(\frac{M_{c r}}{M_{a}}\right)^{3} \cdot J_{g}+\left[1-\left(\frac{M_{c r}}{M_{a}}\right)^{3}\right] \cdot J_{c r} \leq J_{g}
$$

$J_{g}=$ moment of inertia of gross concrete section about centroidal axis, neglecting reinforcement;

$J_{c r}=$ moment of inertia of crecked section transformed to concrete;

$M_{a}=$ maximum moment in member at stage displacement is computed;

$$
M_{c r}=\text { crecking moment }=\frac{f_{t} \cdot J_{g}}{y_{t}}
$$

$y_{t}=$ distance from centroidal axis, neglecting reinforcement;

$f_{r}=$ modulus of rupture of concrete.

Initial displacements are calculated considering the rigidity $E_{d} e$. The result indicates that the ACI method is appropriate for calculation of displacements of RC beams. The ACI method may be improved [5] if the steel areas are included in the calculation of the cracking moment $M_{c r}$

The ACI method [6] diverges enough from the nonlinear model. When the 
load is small and the beam is ithe uncracked state, the method of ACI underestimates the total displacement. This method overestimates the total displacements for higher loads.

The European approach suggests calculation deflection based on curvature integration at many sections along the span. Tension stiffening [7] depends mainly on the bond characteristics of the reinforcement that, depend on many factors including the type of reinforcement elastic Modulus, and Poisson's ratio. Ignoring the tension stiffening significantly reduces the accuracy of the deflection prediction to 56\%. The CEB-FIP Code 1990 (CEB-FIP 2004) [8] interpolates the effective curvature $\kappa_{e}$ between the curvature of the gross and the cracked sections $\kappa_{g}$ and $\kappa_{c r}$, respectively. Both the computed and the measured deflections can be found in [9] Abdelrahman (1995).

Eurocode 2 (ENV 1992-1-1) [10]. The deflection calculation according to Eurocode 2 is generally determined by double integration of the curve $K$ along the length of the element $l$,

$$
v=\iint K(\mathrm{~d} l)^{2}
$$

The proposed procedure is not directly applicable to elements that are exposed to significant axial force. Two methods [11] are suggested for calculating the deflection of both reinforced and prestressed concrete flexural members. In the more rigorous approach, the curvature is calculated at a reasonable number of sections along the beam and then the deflection is calculated by numerical integrations. In the approximate method, the deflection is calculated twice assuming the whole member to be in the uncracked and fully cracked conditions. The following equation is used as a function of the uncracked and fully cracked deflections.

$$
\begin{gathered}
\Delta=\xi \Delta_{\text {II }}+(1-\xi) \Delta_{\mathrm{I}} \\
\xi=1-\beta_{1} \beta_{2}\left(M_{c r} / M_{a}\right)^{2}
\end{gathered}
$$

where $\beta_{1}$ is a coefficient that takes account of bond properties of the bars: 0.5 for plan bars, 1.0 for high bond bars; $\beta_{2}$ is a coefficient of the duration of the loading or of repeated loading, 1.0 is for short-term loading, and 0.5 is for many cycles of repeated loading; $\Delta$ is displacement, $\Delta_{\mathrm{I}}$ displacement calculated on an uncracked section and $\Delta_{\text {II }}$ the displacement calculated on the basis of a cracked section According to CEB [11], the modulus of elasticity of concrete, $E_{\mathcal{o}}$ may be estimated from compressive strength $f_{c}^{*}$, using relationships presented in the design codes.

The present paper has developed an analytical procedure (model) based on energy principles applied very frequently in the past (Pfluger, 1948, Timoshenko and Gere, 1961)

The most comprehensive theoretical review of the Energy method was given by [12] Bažant and Cedolin (2010). The method proposed in this paper covers the tensile zone of concrete. In most papers the equilibrium conditions and moment-curvature relation may be accurately fulfilled at the mid-span of the 
beam only.

This paper includes the integration performed in all the segments along the beam span. By this paper, we intend to affirm the variational principle, the principle of the minimum of potential energy, that is, the principle of virtual displacements, for determining the deformation of elements of concrete structures. The energy potential of the internal stresses and strains along the element is equated with the energy of the external forces for the required deformation. This equalization gives a quadratic equation for the case of axial cross-section force or prestressing force, or a linear equation for the case of moments in cross-section, without axial forces. The expressions for the energy potentials of the internal forces are shown in a general (open) form, with the possibility of numerical integration, which is in fact a free member of the quadratic (linear) equation that directly affects the magnitude of the displacement.

\section{Theoretical Bases and Proposed Model Develop for Determination Displacements of RC \& PSC Beams}

\subsection{Relation between Stresses and Strains in Nonlinear Concrete Theory}

When solving some tasks in the theory of reinforced concrete structures, [13] (Ghali A. and Favre R., 1994) such as deformations problems and theories, nonlinear relationships between stresses and concrete strains are also taken into account. Such nonlinearities are generally applicable to the so-called. Instantaneous deformations, which occur immediately after the change of load i.e. stress, as well as at the temporal deformations of concrete flow, for stress calculation, for pressed concrete, idealized diagram $\sigma_{c}, \varepsilon_{c}$. The analytic diagram $\left(\sigma_{c}, \varepsilon_{c}\right)$ was obtained by dividing the stress ordinates of the characteristic curve by the factor $\alpha, \alpha / \gamma_{c}$ (Figure 1), is given in the form (Equation (3)):

$$
\sigma_{c}=\frac{\beta}{\varepsilon_{c 1}^{2}}\left(2 \varepsilon_{c 1}-\varepsilon_{c}\right) \varepsilon_{c}
$$

$\gamma_{c}$ partial safety coefficient for concrete $\left(\gamma_{c}=1.50\right)$ and $\gamma_{c}=1.30$ for non-random calculating situation, $\alpha=0.85$ coefficient for taking the influence of longacting effects on compressive strength of concrete, $f_{c d}=f_{c k} / \gamma_{c}=\beta$ calculating compressive strength of concrete.

\subsection{Steel for Reinforcing [10]}

According to EC 2 for reinforced concrete structures, all types of steel that meet the EN10080 steel standards can be used. In compliance with this, the thermal coefficient $\alpha=10 \times 10^{-6} \mathrm{C}^{0}$ and the modulus of elasticity $E_{a}=200 \mathrm{kN} / \mathrm{mm}^{2}$ are taken. Calculation diagram stress-strain of steel for reinforcing is a bilinear diagram (Figure 1). For steels with a pronounced flow threshold, the best approximation is achieved by an under-angle branch (ideally elastic-plastic), bilinear diagram. 


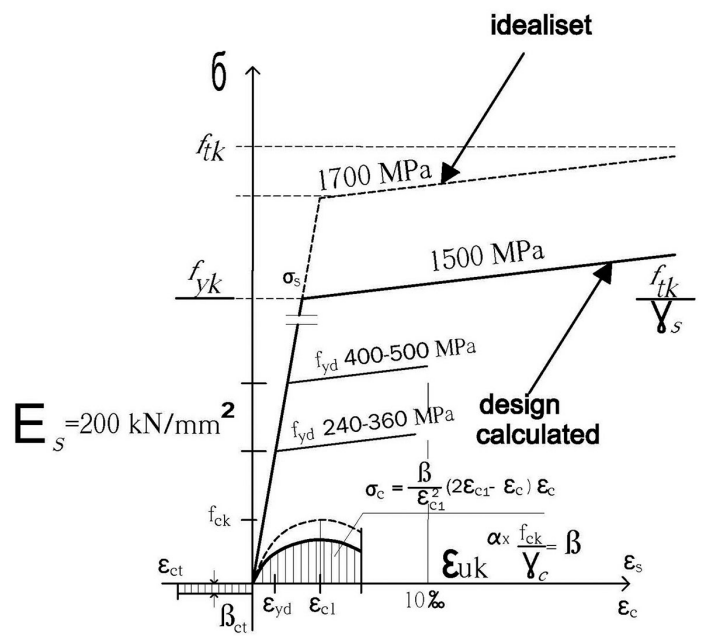

Figure 1. Constitutive relations for concrete EC 2 [10] and steel with bilinear diagrams. The analytic diagram $\left(\sigma_{c}, \varepsilon_{c}\right)$ was obtained by multiply the stress ordinates of the characteristic curve by the factor $\boldsymbol{\alpha}, \boldsymbol{\alpha} / \gamma_{c}$ He strains of compressed and tensile concrete $\varepsilon_{c}$ and $\varepsilon_{c t}$ are shown as curve lines trought the cross section. Diagram stress strain of the steel for reinforcing is adopted a bilinear diagram. For smooth steel is $f_{v k} / f_{t k}=240 / 360 \mathrm{MPa}$. and for ribbed iron is $f_{y k} / f_{t k}=400 / 500 \mathrm{MPa}$. Modulus of elasticity is $E_{s}=$ $200 \mathrm{kN} / \mathrm{mm}^{2}$. Steel for prestressing, bilinear idealiset diagram is obtained by applying the partial coefficient $\mathrm{PN}\left(\gamma_{s}=1.15\right)$ for basic actions. The steel of the cables $\Phi 7 \mathrm{~mm}$ have, $f_{y k} / f_{t k}=1500 / 1700 \mathrm{MPa}$. The strings $\Phi 2.5 \mathrm{~mm}$ have yield stress somethin bigger, $f_{y k} / f_{t k}=1600 / 1900 \mathrm{MPa}$.

The expansion diagrams show us the dependence of the stress from the relative elongation at simple uniaxial tension; they are reached experimentally. Diagram without self-hardening effect in this case is

$$
\begin{gathered}
\sigma_{s}=E_{s} \cdot \varepsilon_{s} \text { at } \varepsilon_{y d}=\frac{f_{y d}}{E_{s}} \\
0 \leq \varepsilon_{s} \leq \varepsilon_{y d}
\end{gathered}
$$

\subsection{Stress and Strains Analysis of Prestressed Elements [10]}

Pre-flow stress and strains $(t=0)$ govern stresses and forces with the index "o". So the stress in concrete is $\sigma_{c k}(0)$, steel for prestressing $\sigma_{s k}(0)$ and steel for reinforceing $\sigma_{s}(0)$

Introducing $n_{k}=E_{k} / E_{c}$ and $n_{s}=E_{s} / E_{c}$ to determine the ideal cross section characteristic, is in effect

$$
\begin{aligned}
B_{i} & =B+n \times A_{i} \\
\Delta e & =e \times n A_{s} / B_{i}
\end{aligned}
$$

$e$-distance of the center of gravity of the concrete from the center of gravity of the steel section

$\Delta e$-distance of the center of gravity of the concrete cross-section to the center of gravity of the idealized cross-section 
$B_{i} J_{i}$ idealized cross-section and moment of inertia.

In the case of adhesion between concrete and steel, the stress in the fiber at the distance $y_{i}$ from the center of gravity is (Equation (6)),

$$
\begin{gathered}
\sigma_{c}^{u, l}=\frac{N_{k}}{B_{i}} \pm \frac{M_{k}}{J_{i}} \cdot y_{i} \\
\sigma_{s}=n \times \sigma_{c, s}^{l} ; \quad \sigma_{s^{\prime}}=n \times \sigma_{c, s^{\prime}}^{u}
\end{gathered}
$$

Concrete strains are valid according to (6a) and pursuant to

$$
\begin{gathered}
\varepsilon_{c}^{2}-2 \varepsilon_{c} \varepsilon_{c 1}+\frac{\sigma_{c} \varepsilon_{c 1}^{2}}{\beta}=0 \\
\beta=\alpha f_{c d} \\
\varepsilon_{c u}=\varepsilon_{c 1}-\varepsilon_{c 1} \sqrt{1-\frac{\sigma_{c}}{\beta}}
\end{gathered}
$$

$\varepsilon_{c}^{u}$ is the upper strain $=\varepsilon_{c}: \quad \varepsilon_{c}^{l}$ is the lower strain.

\subsection{Steel for Prestressing ([10], EC 2) \& [14]}

The mechanical properties for prestressing of steel [10] are defined by the basic parameters of steel $f_{p} 0.1 \mathrm{k}$-characteristic value of the conventional stretching limit to which corresponds irreversible dilatation of $0.1 \%$.

$\varepsilon_{u k}$ : characteristic strain value at maximum stress.

$f_{t k}$ : characteristic value at straining Modulus of elasticity is adopted with a value of $200 \mathrm{kN} / \mathrm{mm}^{2}$.

In compliance with the above, the bilinear idealized diagram shown in Figure 1 is defined. It is recommended to limit the strain of steel to $10 \%$, without explaining whether the tot expansion of cables and straining of the section in the tightened zone are considered. The calculation diagram was obtained by applying the partial coefficient for $\mathrm{PN}(\gamma=1.15)$ for basic actions (Figure 1).

Cables that are strained at a later stage are considered to have high, while pre-straining cables normal ductility.

\section{Virtual Energy Method}

External forces acting on the body, execute action during its deformation. We will assume that this action is accumulated as deformation energy (deformation action, internal force action). If it is desired that no part of the defamation action is converted into kinetic energy and is lost in this way, then it is assumed that loads grow immensely slowly starting from zero. In this case, there will be a balance between external and internal forces at all times.

If the deformation of the body is entirely elastic, then the energy accumulated during the loading is recovered. The deformation action of the internal reactions of the body is obtained if in volume element we put together all contributions and then we integrate them by the volume of the body. Potential energy of the structure [12] is defined according to the principle of the minimum potential 
energy (Bažant and Cedolin 2010).

The potential energy of the structure is defined by the given expressions (7).

$$
\Pi=U-W, \delta \Pi=0, \delta(U-W)=0
$$

Of all possible internal forces that stand in equilibrium with the given external forces, the real forces are those for which the potential $\delta \Pi_{i}$ has a minimum value.

$$
\int_{0}^{V} Y_{i} \delta u_{i} \mathrm{~d} V+\int_{0}^{A} p_{i} \delta u_{i} \mathrm{~d} A=\int_{0}^{V} \sigma_{i j} \delta \gamma_{i j} \mathrm{~d} V
$$

In which the expression

$$
\delta \int_{0}^{V} \sigma_{i j} \delta \gamma_{i j} \mathrm{~d} V=\delta U_{i}
$$

is the change in the free energy (stain internal energy) of the system.

The equalizing the change of the free energy of the system (strain energy) (8a) with (8) potential of the external forces (volume and surface integral), displacement of the structural element is determined.

\subsection{The Strain Energy of the RC Beam Subjected to Bending [15]}

In accordance with the expression (9), the strain energy of compressed concrete along the cross-section is derived from the constitutive relation diagram, calculated by [15] Balabusic and Folic (2015) for concrete and steel (Figure 2).

$$
\begin{aligned}
U_{c}^{(M)} & =\int_{V}\left(\int_{V}^{\varepsilon} \sigma_{c} \mathrm{~d} \varepsilon_{c}\right) \mathrm{d} V \\
& =\int_{l}\left[\int \frac{\beta}{\varepsilon_{c 1}^{2}} \cdot\left(2 \varepsilon_{c 1} \varepsilon_{c}\right) \cdot \varepsilon_{c} \cdot \mathrm{d} \varepsilon_{c}\right] \cdot A_{c} \cdot \mathrm{d} l \\
& =\int^{\varepsilon} \frac{\beta}{\varepsilon_{c 1}^{2}} \cdot\left(\varepsilon_{c 1}-\frac{\varepsilon_{c}}{3}\right) \cdot \varepsilon_{c}^{2} \cdot x_{b} \cdot b \cdot \mathrm{d} l
\end{aligned}
$$

Strain $\varepsilon_{c}$ of compressed concrete exposed to bending is obtained from the equilibrium condition (see Equation (19, 19a, 19b).

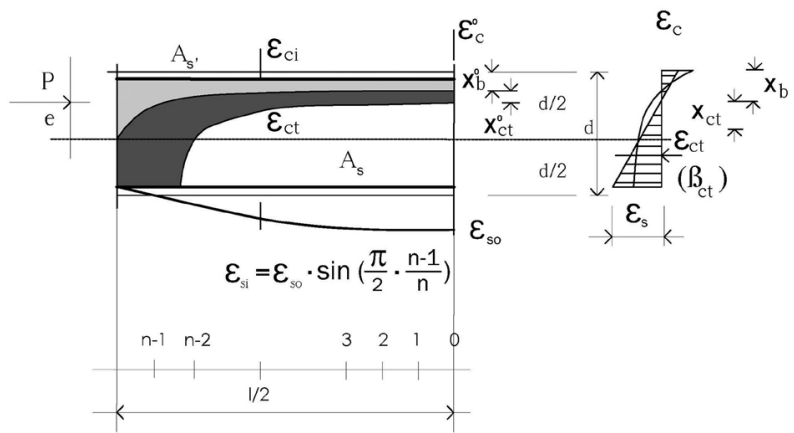

Figure 2. Represents the strains at the cross-section and the strains along the beam; the strain $\varepsilon_{s}$ of tensile reinforcement is represented as a sine function. The strains of compressed and tensile concrete $\varepsilon_{c}$ and $\varepsilon_{c t}$ are shown in curve lines along the beam. 
The strain energy at the ith section of compressed concrete after numerical integration along entire length of the beam by trapezoidal rule is finally given as,

$$
\begin{gathered}
U_{c i}^{(M)}=\frac{1}{2} \cdot \beta \cdot \varepsilon_{c 1} \cdot x_{b} \cdot b \cdot\left(1-\frac{\delta}{3}\right) \cdot \delta^{2} ; \delta=\frac{\varepsilon_{c}}{\varepsilon_{c 1}} \\
U_{c}^{(M)}=\left(U_{c, 0}^{(M)}+2 \cdot \sum_{i=1}^{n-1} U_{c, i}^{(M)}\right) \frac{l}{2 n}
\end{gathered}
$$

\subsection{Strain Energy Transmitted through Tensile and Compressive Reinforcement}

The strain energy of tensile and compressive reinforcement [15] is given by

$$
U_{s}^{(M)}=\int_{l}\left[\int_{0}^{l} \sigma_{e} \mathrm{~d} \varepsilon_{e}+\int_{0}^{l} \sigma_{p} \mathrm{~d} \varepsilon_{p}\right] A_{i} \mathrm{~d} l
$$

The following notations have been used in expressions (8), where $\sigma_{e}$ is the stress in steel for the case $\varepsilon_{s}<\varepsilon_{y d} \quad \sigma_{p}$ represents stress in steel for the case $\varepsilon_{s}>\varepsilon_{y d}$.

The approximation of tensile reinforcement $\varepsilon_{s i}$ strain by the sine function (Figure 2) is accepted per sections along the beam:

$$
\varepsilon_{s i}=\varepsilon_{s o} \times \sin \frac{\pi}{2} \times \frac{n-i}{n}, \quad i=0,1, \cdots, n-1 ; n \text {-number of sections }
$$

The strain $\varepsilon_{\text {so }}$ stated in Equation (12) represents the maximum strain of the steel in central section of simple beam.

The strain energy transmitted by tensile reinforcement [15] per section is:

$$
U_{s i}^{(M)}=A_{s} \cdot f_{y d} \cdot\left[\varepsilon_{s}-\frac{\varepsilon_{y d}}{2}\right] ; \varepsilon_{s}>\varepsilon_{y d}
$$

Per section is:

$$
U_{s i}^{(M)}=\frac{1}{2} \cdot A_{s} \cdot f_{y d} \cdot \frac{\varepsilon_{s}^{2}}{\varepsilon_{y d}} ; \varepsilon_{s}<\varepsilon_{y d}
$$

Per volume integral

$$
U_{s}^{(M)}=\left(U_{s 0}^{(M)}+2 \sum_{i=1}^{n-1} U_{s i}^{(M)}\right) \frac{l}{2 n}
$$

The strain energy that is transmitted by compressive reinforcement is:

$$
\begin{gathered}
U_{s i^{\prime}}^{(M)}=\frac{1}{2} \cdot A_{s} \cdot f_{y d} \cdot \frac{\varepsilon_{c}^{2}}{\varepsilon_{y d}} \cdot\left(\frac{x_{b}-a^{\prime}}{x_{b}}\right)^{2} ;\left(\frac{x_{b}-a^{\prime}}{x_{b}}\right) \cdot \varepsilon_{c}<\varepsilon_{y d} \\
U_{s^{\prime}}^{(M)}=\left(U_{s^{\prime} 0}^{(M)}+2 \sum_{i=1}^{n-1} U_{s^{\prime} i}^{(M)}\right) \frac{l}{2 n}
\end{gathered}
$$

\subsection{The Strain Energy of the Prestressed Concrete (PSC) Beams [15]}

The integration is performed directly per volume because the strain energy is 
changeable or constant along the section of the beam. Diagram as a difference of the strain energies of the compressed and tensile concrete are:

For the simple beam,

$$
U_{c, i}^{N_{k}}=\beta \cdot \varepsilon_{c 1} \cdot b \cdot d \cdot\left(1-\frac{\delta^{u}}{3}\right) \delta^{u 2}-\frac{1}{2} \cdot \beta \cdot \varepsilon_{c 1} \cdot b \cdot d \cdot\left(1-\frac{\delta^{u}-\delta^{l}}{3}\right)\left(\delta^{u}-\delta^{l}\right)^{2}
$$

or the cantilever beam

$$
\begin{aligned}
& U_{c, i}^{N_{k}}= \beta \cdot \varepsilon_{c 1} \cdot b \cdot d \cdot\left(1-\frac{\delta^{l}}{3}\right) \delta^{l 2} \\
&-\frac{1}{2} \cdot \beta \cdot \varepsilon_{c 1} \cdot b \cdot d \cdot\left(1-\frac{\delta^{l}-\delta^{u}}{3}\right)\left(\delta^{l}-\delta^{u}\right)^{2} \\
&+\frac{1}{2} \sigma_{y d} \cdot\left(\frac{x_{e}-a^{\prime}}{x_{e}}\right)^{2} \cdot \varepsilon_{c}^{2} \cdot A_{c} ; \frac{x_{e}-a^{\prime}}{x_{e}} \varepsilon_{c} \leq \varepsilon_{y d}\left(=U_{s i}^{N_{k}}\right) \\
&+\frac{1}{2} \sigma_{y d} \cdot\left(\frac{h-x_{e}}{d-x_{e}} \cdot \frac{1-\alpha}{1+\alpha}\right)^{2} \frac{\varepsilon_{c}^{2}}{\varepsilon_{y d}} \cdot A_{c} \quad\left(=U_{s i}^{N_{k}}\right) \\
& \delta^{u}=\frac{\varepsilon_{c}^{u}}{\varepsilon_{c 1}}, \delta^{l}=\frac{\varepsilon_{c}^{l}}{\varepsilon_{c 1}}
\end{aligned}
$$

Whereat upper and lower steel strains

$$
\begin{gathered}
\varepsilon_{s}^{u}=\frac{x_{e}-a^{\prime}}{x_{e}} \varepsilon_{c} \\
\varepsilon_{s}^{l}=\frac{h-x_{e}}{d-x_{e}} \frac{1-\alpha}{1+\alpha} \varepsilon_{c}
\end{gathered}
$$

After integration along the prestressed beam and by use of the trapezoidal rule, we obtain strain energy for concrete and steel.

$$
\begin{aligned}
& U_{c}^{N_{k}}=\left(U_{c, 0}^{N_{k}}+2 \cdot \sum_{i=1}^{n-1} U_{c, i}^{N_{k}}\right) \frac{l}{2 n} \\
& U_{s}^{N_{k}}=\left(U_{s, 0}^{N_{k}}+2 \cdot \sum_{i=1}^{n-1} U_{s, i}^{N_{k}}\right) \frac{l}{2 n}
\end{aligned}
$$

\subsection{Strain Energy of Tensile Concrete of the RC Beam Subjected to Bending}

The strain energy of tensile concrete per cross-section is derived in accordance with the constitutive relations Equation (8) and equilibrium condition (Figure 2) expressions (see Equation (17)-(19), later)

$$
U_{c t, i}^{(M)}=\beta_{c t} \cdot \varepsilon_{c t} \cdot x_{c t} \cdot b \cdot \frac{l}{2}
$$

The limiting values of the strength and strain of concrete at tension, based on CEB (1990) and CEN (2004) [8] [11] [16] are:

$$
\beta_{c t}=0.25 \cdot \beta^{2 / 3} \cdot\left(0.6+0.4 \cdot d^{1 / 4}\right)
$$




$$
\begin{gathered}
\varepsilon_{c t}=\left(f_{c t} /\left(0.4 \cdot 9.25 \cdot\left(f_{c k}+9.5\right)^{1 / 3}\right.\right. \\
x_{c t}=\varepsilon_{c t} / \varepsilon_{s} \cdot\left(h-x_{b}\right)
\end{gathered}
$$

After integration along the beam and by use of trapezoidal rule, it is:

$$
U_{c t}^{(M)}=\left(U_{c t, 0}^{(M)}+2 \cdot \sum_{i=1}^{n-1} U_{c t, i}^{(M)}\right) \frac{l}{2 n}
$$

\section{Equilibrium Conditions [10] EC 2}

The strains in the sections have been defined by adopting the tensile reinforcement strain $\varepsilon_{s}$ and the $N\left(\varepsilon_{c}\right)$ force from the equilibrium conditions (Equation (19), later). From the proposed tensile reinforcement strain $\mathcal{E}_{s}$ and responsible force $N\left(\varepsilon_{c}\right)$, it is necessary to define the compressive and tensile concrete strains $\left(\varepsilon_{b}, \varepsilon_{c t}\right)$ of the beam's cross-sections. (Figure 2) The dimensionless values (Equation (17) of the internal normal force $n_{u}$ and the internal bending moment $m_{u}$ are:

$$
m_{u}=n_{u} \cdot \frac{e}{h}=\frac{M}{b h^{2} f_{c k}} ; n_{u}=\frac{N}{b d f_{c k}}
$$

$e$ is the eccentricity of the external normal force.

Equation (21) represents the eccentricity of the selected beam section, thus it is represented by the sine function along the beam in the corresponding Equation (18).

$$
e_{i}=e_{0} \cdot \sin \frac{\pi}{2} \cdot \frac{n-i}{n}, n=0,1,2, \cdots, n-1
$$

The value $e_{0}$ stated in Equation (18) represents the maximum eccentricity in the middle of the beam. As to well-known equilibrium conditions, the equality of forces and moments of the RC\& PSC beams must be met in each selected section.

$$
\begin{gathered}
\sum_{k=0}^{n} N=0, D_{b}+D_{s^{\prime}}-D_{c t}=Z_{s}+N \\
\sum_{k=0}^{n} M=0, \sum_{0}^{n} z \cdot D_{i}=v \cdot M \\
\frac{s \varphi\left(1-\frac{\varphi}{3}\right)-n_{u}}{\sigma_{s}-k \sigma_{s^{\prime}}}=\frac{m_{u}-\frac{1}{2}(1+\alpha) s \varphi\left(1-\frac{\varphi}{3}\right)+\frac{1}{3}\left(1-\frac{\varphi}{4}\right) \varphi s^{2}}{\frac{1}{2}(1-\alpha)\left(\sigma_{s}+k \sigma_{s^{\prime}}\right)} \\
\text { hereat: } s=\frac{\varphi}{D+\varphi}, \quad D=\frac{\varepsilon_{s}}{\varepsilon_{c 1}} ; \quad m_{u}=\frac{M}{b h^{2} \beta} ; k=\frac{A_{s^{\prime}}}{A_{s}} \\
\sigma_{s^{\prime}}=210 \cdot \varepsilon_{c 1} \cdot \varphi \cdot \frac{s-\alpha}{s} ; \quad \sigma_{s}=210 \cdot \varepsilon_{c 1} \cdot \varphi \cdot \frac{1-s}{s}
\end{gathered}
$$

Neutral axis is: $x_{b}=s h$

The internal force $N$ belongs to the condition with defined stresses and strains and it is included into the moment-bending condition $\Sigma M=0$, corresponding to 
axial strain energy.

Equation (19) and (19a) serves to determine the strains of compressed and tensile concrete $\varepsilon_{c}, \varepsilon_{c t}$, and neutral axis for the adopted strain of tensile reinforcement $\varepsilon_{\mathrm{s}}$ as an independent variable.

\section{Energy Potential of External Forces}

According to [12] Bazant Z.P. and Cedolin L. the value of the integral is (Figure 3),

$$
W_{i}=\int_{0}^{V} Y_{i} u_{i} \mathrm{~d} V+\int_{0}^{A} p_{i} u_{i} \mathrm{~d} A
$$

Energy of external forces is

$$
W_{i}=\int_{0}^{l} q(x) u(x) \mathrm{d} x-P_{i} \int_{0}^{l} \frac{\varepsilon_{s}-\varepsilon_{c}}{h} \mathrm{~d} x
$$

Uniform load expressed as a function of bending moment in cross-section,

$$
q_{i}=-\frac{\partial M(x)^{2}}{\partial x^{2}}
$$

Therefore after two partial integrations, for boundary conditions

$$
x=0, x=l, M_{i}=0, u(x)=0
$$

for

$$
\kappa(x)=\frac{\partial^{2} u(x)}{\partial^{2}(x)}=\frac{\varepsilon_{s}+\varepsilon_{c}}{h}
$$

and the normal force in the cross-section $N_{i}=-P_{i}$ gives the external energy as a function of the intersecting forces (moments and axial forces) and strains,

$$
W_{i}=\int_{0}^{l}\left[M(x) \frac{\varepsilon_{s+} \varepsilon_{c}}{h}+N(x) \frac{\varepsilon_{s}-\varepsilon_{c}}{h}\right] \mathrm{d} x
$$
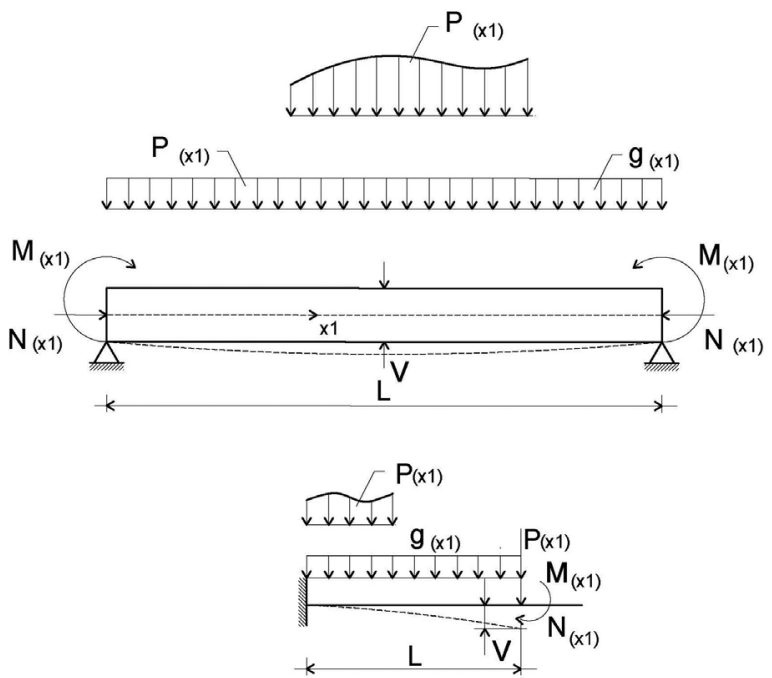

Figure 3. External Loads of Reinforced \& Prestressed (simple and cantilever beam). 
In order to determine the deformation (displacement) of a structural element (Simple and Cantilever Beams), it is necessary to adopt a deformation line,

$$
\eta(\xi)=v \cdot \sin \pi \xi
$$

where $v$ is usually the maximum displacement, then the energy of external forces can be expressed (Figure 3).

For SIMPLE BEAM

$$
\begin{aligned}
W_{i}= & \frac{2}{\pi} q_{y} l \cdot v+\sum_{i=1}^{n} P_{i y} \sin \pi \xi \cdot v+\sum_{i=1}^{n} M_{i z} \frac{\pi}{2} \cos \pi \xi v \\
& -N_{p k} \frac{v^{2}}{l / 2}-M_{p k} \cdot \frac{2}{\pi} \frac{v}{l}
\end{aligned}
$$

For CANTILEVER BEAM applies:

$$
\begin{aligned}
W_{i}= & \left(1-\frac{2}{\pi}\right) q_{y} l \cdot v+\sum_{i=1}^{n} P_{i y} \frac{1-\cos \pi \xi}{2} v+\sum_{i=0}^{n} M_{i z} \frac{\pi}{2 l} \sin \pi \xi \cdot v \\
& -N_{p k} \frac{v^{2}}{l}-M_{p k}\left(1-\frac{2}{\pi}\right) \frac{v}{l}
\end{aligned}
$$

Whereby are uniform load, $P_{i y}$ concentrated forces, $M_{i z}$ concentrated moments at element (rod). $N_{p k}$ : prestressing force in cross-section.

$M_{p k}$ : moment from the prestressing force in the element.

$v$. displacement of the deflection of a structural element.

EXAMPLE NUMBER 1, D. Jeftić. 1979. [17], Prestressed beam,

Comparison experimental results with virtual principle method

In Figure 4, the cross-section and static diagram of the prestressed beam girder (bracket) are shown, which was examined by Prof. D, Jevtić [17].

The beam was prestressed on the track, and the release was performed 8 days after the concrete was embedded. At the period of 40 days, the beam has been loaded with its own weight $g=0.295 \mathrm{kN} / \mathrm{mL}$ and force $P=2.07 \mathrm{kN}$ at the free end of the console (cantilever), which amounted to $42 \%$ of fracture force $P_{u}$. Concrete strength after 28 days $f_{c k}=55.0 \mathrm{MPa}$. The force of the previous stress is $N_{k}=93.60 \mathrm{kN}$.

Prestressing steel strength is $f_{y k}=1600 \mathrm{MPa}$, while the max is the elastic strain of the steel $\varepsilon_{y k}=8.0 \times 10^{-3}$. Number and diameter of prestressing wires is $A_{k}=18$ $\Phi 2.50 \mathrm{~mm}\left(A_{k}=0.8836 \times 10^{-4} \mathrm{~cm}^{2}\right)$.

The cross-sectional area of the concrete is $A_{c}=118 \mathrm{~cm}^{2}$, moment of inertia ideals. It is a cross section $J_{c i}=1656 \mathrm{~cm}^{4}$.

The task of this numerical example is to determine the initial displacement of the end of the prestressed beam by the energy method and compare it with the experimental results.

Basic (initial) static influences in console clamping $M_{g}=0.590 \mathrm{kN} \cdot \mathrm{m}$, $M_{p}=2.07 \times 2.0=4.14 \mathrm{kN} \cdot \mathrm{m}, \quad M_{k}=93.8 \times 0.0153=1.432 \mathrm{kN} \cdot \mathrm{m} \quad$ where the difference between the center of gravity of the cables and the center of gravity of the cross section is $\Delta e_{k}=9.39-7.86=1.53 \mathrm{~cm}$, so that the total clamping moment is $M_{4}=3.248 \mathrm{kN} \cdot \mathrm{m}$, 


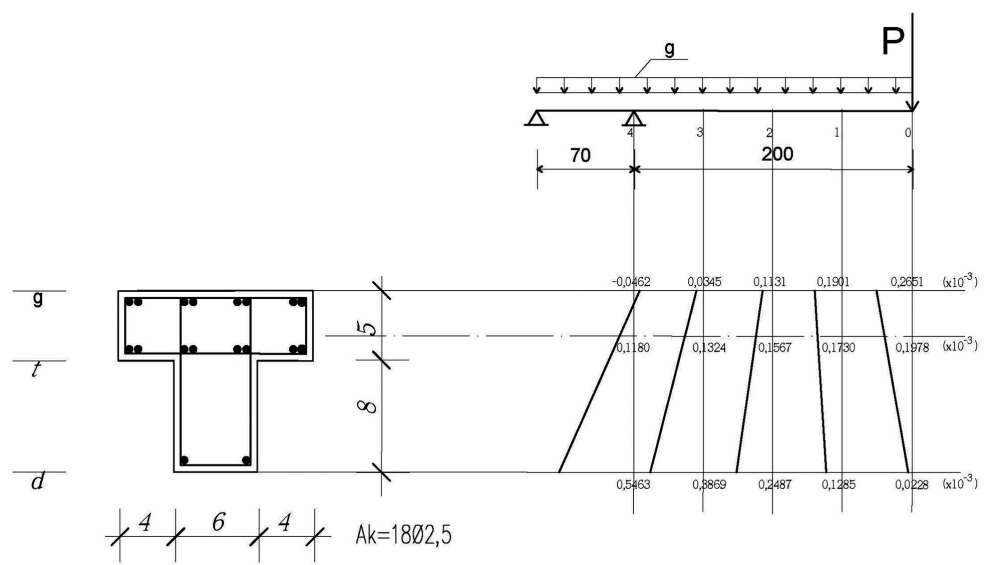

Figure 4. Prestressed cantililever beam [17], D. Jeftić, experimental mode with concrete and steel strains.

In Table 1 moments in cross sections, edge strains (upper and lower) of concrete are shown in $\mathcal{E}_{c \text { p }}$ as well as strains in the direction of the prestressing force $\varepsilon_{k i}^{\left(N_{k}\right)}$.

According to Equation (15), we get dilatation energy $U_{c i}$ concrete cross-section of prestressed beams and especially (15a) energy $U_{s i}$ in prestressed wires.

The expansion energy of the girder, along the length of the structure, was obtained after integration with the Trapezoidal rule (15b).

From Equation (15b):

$$
U_{c}^{N_{k}}=33.6948 \times 10^{-3} \mathrm{kN} \cdot \mathrm{m} ; \quad U_{s}^{N_{k}}=0.43537 \times 10^{-3} \mathrm{kN} \cdot \mathrm{m}
$$

The energy of external forces according to (27) is,

$$
\begin{aligned}
W_{i}= & 0.36338 \times 0.295 \times 2.0 \times v+2.07 \times v+93.6 \times v^{2} / 2.0 \\
& -1.432 \times 0.36338 / 2.0 \times v \\
= & 46.8 v^{2}+2.0242 v
\end{aligned}
$$

By equalizing the external and internal energy of the prestressed beam, a quadratic equation is obtained $v^{2}+0.043282 v-0.000801=0$ with one of the solutions: $V=14 \mathrm{~mm}$, which corresponds perfectly to experimentally measured result.

EXAMPLE NUMBER 2. Assoc. Prof. Baderul Hisham Ahmad (2015)

Prestrssed Concrete Design (SAB 4323) Deflections [14] [18] (overtop)

Comparatinon of calculate results (PSC Beam) and Virtual principle method.

The effect of deflection in structure varies according to the use of the structure. [14]. Short term deflections occur immediately upon the application of load (caused by elastic deformation of the concrete in response to loading), can use various methods to calculate displacement, due to external loads and due to prestressed force.

Double Integration Method, Moment Area Method, Conjugate Beam method and Principle of Virtual Load:

a). Calculation of Assoc. Prof. Baderul Hisham Ahmad, Short-term deflection. 
At Transfer, deflection (camber), due to pure prestress force, Figure $5=-0.0605$ $\mathrm{m}$ (overtop).

Whereat: $N_{k}=6800 \mathrm{kN}, M_{k}=6800 \times 0.26=1768 \mathrm{kN}$;

$A_{c}=0.4596 \mathrm{~m}^{2}, E_{c, 28}=28 \mathrm{kN} / \mathrm{mm}^{2}, J_{c}=0.06396 \mathrm{~m}^{4}$;

$f_{c k}=40 \mathrm{MPa}\left(=f_{c u, 28}\right)$.

b). Calculation by Principle of Virtual Load at Table 2 are shown moments in the sections, upper an lover strains on the edge of the sections, strain energy of the sections and finally energy along the beam at Figure 5 are not shown the strains of pure prestress force because that energy is neglected (about 1\%).

Table 1. Example number 1.

\begin{tabular}{ccccccc}
\hline & 4 & 3 & 2 & 1 & 0 & \\
\hline$M_{i}$ & 3.248 & 2.009 & 0.7855 & -0.3671 & -1.432 & {$[\mathrm{kNm}]$} \\
$\varepsilon_{c i}^{(u)}$ & -0.0462 & 0.0345 & 0.1131 & 0.1901 & 0.2651 & {$\left[\times 10^{-3}\right]$} \\
$\varepsilon_{c i}^{(l)}$ & 0.5463 & 0.3869 & 0.2487 & 0.1285 & 0.0228 & {$\left[\times 10^{-3}\right]$} \\
$\varepsilon_{k i}^{\left(N_{k}\right)}$ & 0.1180 & 0.1324 & 0.1567 & 0.1730 & 0.1978 & {$\left[\times 10^{-3}\right]$} \\
$U_{c i}^{N_{k}}$ & 33.3114 & 24.0114 & 15.645 & 5.3218 & 11.5188 & {$\left[\times 10^{-3}\right]$} \\
$U_{s i}^{N_{k}}$ & 0.12303 & 0.1544 & 0.21703 & 0.26443 & 0.34575 & {$\left[\times 10^{-3}\right]$} \\
\hline
\end{tabular}

Table 2. Example number 2.

\begin{tabular}{cccccc}
\hline & 3 & 2 & 1 & 0 & \\
\hline$M_{i}$ & 0.00 & 883.53 & 1768 & 1768 & {$[\mathrm{kNm}]$} \\
$\varepsilon_{c i}^{(u)}$ & 0.3290 & 0.5605 & 0.8382 & 0.8382 & {$\left[\times 10^{-3}\right]$} \\
$\varepsilon_{c i}^{(l)}$ & 0.3290 & 0.1253 & -0059856 & -0.59856 & {$\left[\times 10^{-3}\right]$} \\
$U_{c i}$ & 115.06 & 122.9689 & 294.6134 & 294.6134 & {$\left[\times 10^{-3]}\right.$} \\
\hline
\end{tabular}

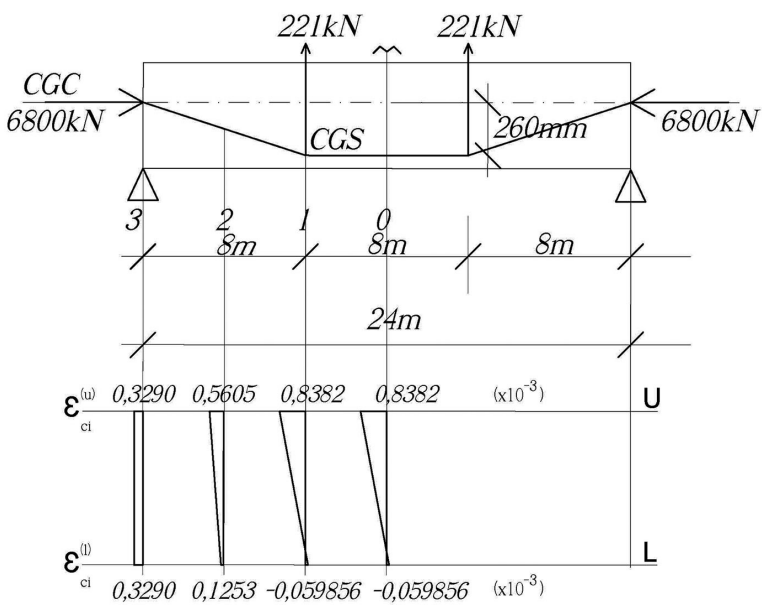

Figure 5. Prestressed concrete beam [8] [14] (overtop), calculation model with concrete strains. 


$$
\begin{aligned}
& U_{c i}=45.060 \times(0.071201-0.043933)=122.9689\left[\times 10^{-3}\right] \\
& U_{c}=(115.06+2 \times(122.9689+294.6134+294.6134+294.6134 \\
&+294.6134+122.9689)+115.06)(24.0 / 6) / 2\left[\times 10^{-3}\right] \\
&= 49.81072 \mathrm{k}
\end{aligned}
$$

By equalizing energy of the external forces (26) and the strain energy (15) in the case of simple beam, we obtain displacement $v$. Influence of the strain energy of steel (prestressed force) may be neglected. It's only about $1 \%$.

$6800 \cdot \frac{2}{24.0} \cdot v^{2}+442.0 \cdot \sin 60^{\circ} v=49.81072 \Rightarrow v=-11.0 \mathrm{~mm}$, overtop.

These two results have a great disagreement. (82\%)

EXAMPLE NUMBER 3. Magda I. Mousa (2015)

Reinforced Concrete Beam [19] [20]

\section{Comparative experimental results with Virtual Principle Method}

An experimental program has been conducted in order to investigate the flexural behavior and ductility of high strength concrete beams with variable length of tension [17] reinforcement lap splice,

The tested beams are of $220 \mathrm{~cm}$ total length and $20 \times 15 \mathrm{~cm}$ cross-section, with reinforcing by $4 \Phi 12 \mathrm{~mm}$ and concrete strength $f_{c u}=65 \mathrm{MPa}$, at middle third loaded with two (65 kN/2 and $75 \mathrm{kN} / 2$ ) equal concentrated loads (Figure 6).

The first yield displacement, $\Delta y$, corresponds to the intersection of the tangents to the load-displacement.

The load-defection curves can be classified into three distinct zones; the first zone is the initial part of the curve up to the cracking point, the post-cracking zone, continued up to the yielding point, and the post-yield zone, up the failure.

The task of this example is to determine displacement in the middle of the reinforced concrete simple beam when steel strain $\mathcal{E}_{s}$ is at the cracking point and on the post-yield zone, up the failure. It will be compared and checked with experimental results of this paper [15] (Figure 7).

a.1) The cracking point for steel strain $\varepsilon_{s}=3.60 \%$ and on the post-yield zone, up to failure $\varepsilon_{s}=14.40 \%$ o, $\mathcal{E}_{c 1}=2.0 \%$.

For two equal forces $65 \mathrm{kN} / 2$ and $75 \mathrm{kN} / 2$, after solving Equation (19a) in accordanc with $(19,19 \mathrm{~b})$, as the polynom of 5 -th degree, we obtain the position of the neutral axis of reinforced concrete section, the value of concrete strain $\mathcal{E}_{\mathcal{c}}$, strain energies of the sections and finally by trapezoidal rule strains energies along the beam.

a.1.1) For steel strain $\varepsilon_{s}=3.60 \%$ at the cracking point: $P=65.0 \mathrm{kN}, m_{u}=$ 0.06964, then

$$
\varphi^{5}+4.46647 \varphi^{4}-3.09329 \varphi^{3}-81.66667 \varphi^{2}+7.30952 \varphi+10.95774=0
$$

one of the roots is: $\varphi=0.4129, s=0.1866, x_{b}=3.3586 \mathrm{~cm}$.

In accordance with (15), (15a) and (15b) we obtain:

$U_{c 1}=0.048144 \mathrm{kN}, U_{s 1}=0.294046 \mathrm{kN}$. 


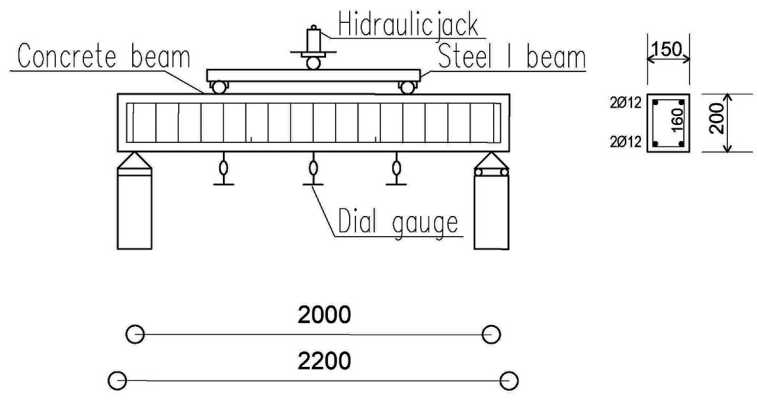

all dimensions in $\mathrm{mm}$

Figure 6. Dimension and details of test model [15] (reinforcement and concrete).

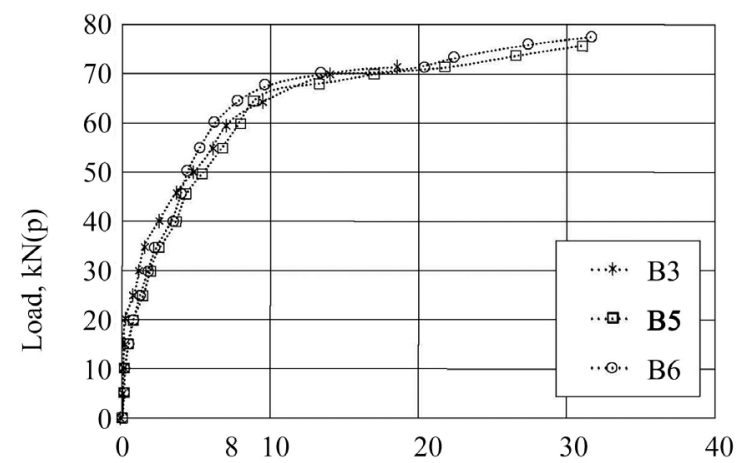

Deflection, $\mathrm{mm}(\Delta)$

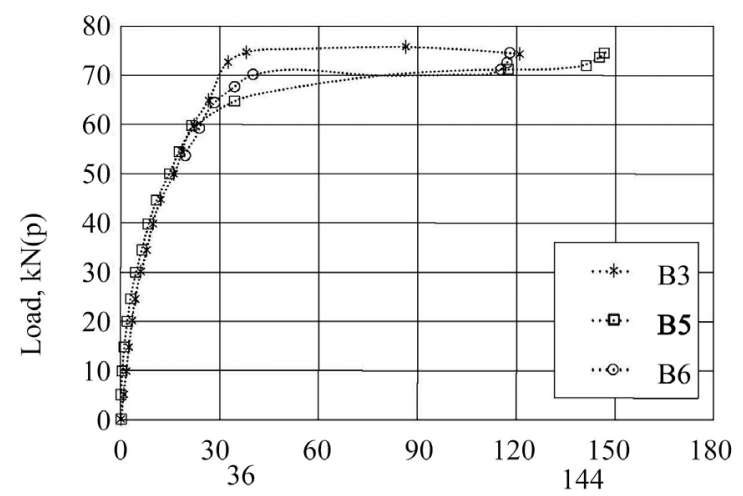

Steelstrain $\times 10^{4}$

Figure 7. Experimental [15]. Load-deflection relationship (group 3) and load-steel strain relationship.

Integration by trapezoidal rule:

$U_{c+s}=U_{c}+U_{s}=0.0641950+0.392061=0.456276 \mathrm{kN} \cdot \mathrm{m}$

a.1.2) Steel strain $\mathcal{E}_{s}=14.40 \%$, post yield zone, up to failure: $P=75.0 \mathrm{kN}, m_{u}=$ 0.07914

$$
\begin{aligned}
& \phi^{5}+7.09287 \phi^{4}-104.013036 \phi^{3}-242.569667 \phi^{2} \\
& +23.736721 \phi-142.423980=0
\end{aligned}
$$


one of the roots is: $\varphi=0.8791, s=0.10881, x_{b}=1.95861 \mathrm{~cm}$.

In accordance with (15), (15a) and (15b) we obtain:

$U_{c 1}=0.104335 \mathrm{kN} ; U_{s 1}=1 / 2 \times 2.26219 \times 400,000.00 \times 2.0+2.2619 \times$ $500,000.00 \times 12.40=1.492-856$.

$$
U_{c+s}=0.139113+1.990475=2.129588 \mathrm{kN} \cdot \mathrm{m}
$$

Equalizing energy of the external forces (26) and the strain energy (15b) in the case of simple beam, we obtain displacement.

$$
\begin{aligned}
& \mathcal{E}_{s}=3.60 \% \mathrm{o}: \frac{2}{\pi} \cdot 0.750 \cdot \ell \cdot v+65.0 \cdot \sin 60^{\circ} \cdot v=0.45626 \Rightarrow v=8.0 \mathrm{~mm} . \\
& \mathcal{E}_{s}=14.40 \% \mathrm{0}: \frac{2}{\pi} \cdot 0.750 \cdot \ell \cdot v+75.0 \cdot \sin 60^{\circ} \cdot v=2.129588 \Rightarrow v=32.3 \mathrm{~mm} .
\end{aligned}
$$

These results given by Principle of Virtual Load correspond with experimental results taken from the original article [14] (Figure 7).

\section{Conclusions}

The main objective of this paper is to present a theoretical and analytical model that determines the elastic and inelastic structural response, strains and strength with the finally initial displacement of the simple and cantilever RC \& PCT beams. The proposed method defines clearly the initial displacements of reinforced and prestressed beams with calculation strains and strain energy along with the member.

The effective flexural rigidity proposed in this paper covers the tensile zone of concrete, which produces a more realistic estimation of curve section and element deformation. The presented method with calculation strain and stresses along the beam including axial forces and bending moments, avoid calculation the member stiffness with defining approximate value the modulus of elasticity. At first and third example is noticed significantly agreement, experimental and calculated results by virtual principle method, on PSC and RC beams. Also calculated results of PSC girder as simple beam have a great disagreement, with results obtained by virtual principle method. The cause is in stiffness EJ which is given as constant, but in fact, it is a complex function smaller than adopted flexural rigidity and displacements calculated by the present virtual method have a bigger value.

\section{Acknowledgements}

The author gratefully acknowledges the support provided by "KRUŠO" BUILDING COMPANY OF MONTENEGRO with Presiden and owner Slobodan Radović Krušo. Moreover, the author would like to thank Academic, prof. Dr. Radomir Folic for his assistance and proofreading the paper.

\section{Conflicts of Interest}

The author declares no conflicts of interest regarding the publication of this paper. 


\section{References}

[1] Branson, D.E. and Shaikh, A.F. (1985) Deflection of Partialy Prestressed Members. SP-86, American Concrete Institute, Detroit, 323-363.

[2] ACI Committee 318 (1995) Building Code Requirements for Structural Concrete (ACI 318-95) and Commentary (ACI 318R-95), American Concrete Institute, Detroit, $369 \mathrm{p}$.

[3] ACI Committee 435 (1966) Deflections of Reinforced Concrete Flexural Members. ACI Journal, Proceedings, 63, 637-674.

[4] ACI Committee 435, Subcommittee 5, Scordelis, A.C. Branson, D.E., and Sozen, M.A. (1979) Deflections of Prestressed Concrte Members. Manual of Concrete Practice, ACI 435.1R-63 (Reapproved 1979), pp. 2-14.

[5] Cervenka, V. (1985) Constitutive Model for Cracked Reinforced Concrete. International Concrete Abstracts Portal, 82, 877-882. https://doi.org/10.14359/10409

[6] Araujo, J.M. (1991) A Model for Analysis of Reinforced Concrete Beams. Portuguese Magazine of Structural Engineering, No. 32, Lisbon, Portugal, 9-14.

[7] Aly, R. (2007) Stress along Tensile Lap-Spliced Fiber Reinforced Polymer Reinforcing Bars in Concrete. Canadian Journal of Civil Engineering, 34, 1149-1158. https://doi.org/10.1139/107-046

[8] Comite' Euro Internatonal du Beton (CEB) and Federation Internationale de la Precontrainte (FIP) (1990) Model Code for Concrete Structures. Comite' Euro Internatonal du Beton, 6.rue Lauriston, F-75116, Paris.

[9] Abdelrahman, A.A. (1995) Serviceability of Concrete Beams Prestressed by Fibre Reinforced Plastic Tendonds. PhD Thesis, Department of Civil, Geological and Environmental Engineering, University of Manitoa, Winnepeg, 331.

[10] European Committee for Standardization-Eurocode 2 (2003) Design of Concrete Structures. Part 1-1: General Rules and Rules for Buildings, Final Draft, 223 p.

[11] Comite Euro-International du Beton (CEB) (1985) Design Manual on Cracking and Deformations. Comite Euro-International du Beton, Lausnane.

[12] Bažant ZP and Cedolin L. (2010) Stability of Structures: Elastic, Inelastic, Fracture and Demage Theiries. World Scientific Publishing, Politecnico di Milano, Italy.

[13] Ghali A. and Favre R. (1994) Concrete Structures and Deformations. 2nd Edition, E \& FN Spon, London.

[14] Branson, D.E. and Trost, H. (1982) Application of I-Effective Method in Calculating Deflections of Partially Prstressed Members. PCI Journal, 27, 86-111. https://doi.org/10.15554/pcij.09011982.62.77

[15] Balabušić M., Folić R. (2015) Energy Analysis of the Critical Force of Slender RC Columns. Proceedings of the Institution of Civil Engineers-Structures and Buildings, 168, Paper No. 1300064. https://doi.org/10.1680/stbu.13.00064

[16] CEN (European Committee for Standardization) (2004) EN 1992; Design of Concrete Structures, Part 1-1: General Rule and Rules for Buildings. European Committee for Standardization, Brussels.

[17] Jevtić, D. (1979) Prednapregnuti Beton. Knjiga 1, Građevinska Knjiga, Beograd, 401403.

[18] Ahmad, B.H. (2015) Prestressed Concrete Design. (SAB 4323) Deflections, UTM Opencoursewre, Matrix Structural Analysis. Malaysia, Johor Bahru.

[19] Mousa, M.J. (2015) Flexural Behaviour and Ductility of High Strength Concrete 
(HSC) Beams with Tension Lap Splice. Alexandria Engineering Journal, 54, 551-563. https://doi.org/10.1016/j.aej.2015.03.032

[20] Park, R. (1989) Evaluation of Ductility of Structures and Structural Assemblages from Laboratory Testing. Bulletin of the New Zealand Society for Earthquake Engineering, 22, 155-166. https://doi.org/10.5459/bnzsee.22.3.155-166 